\title{
Transfer of compound and component solution modes
}

\author{
TIMOTHY R. BARNES, EILEEN M. CASSIDY, JOANN M. NINFA \\ MARGARET M. YAGO, and MARSHA J. BARNES \\ Rosemont College, Rosemont, Pennsylvania 19010
}

\begin{abstract}
The present experiment compares the shift performance of four groups on the following types of shift problems: a component problem following a previous component problem with a different relevant dimension, a component problem following a compound problem, a compound problem following a previous compound problem with a different relevant dimension, and a compound problem following a component problem. Facilitation of shift performance was found following prior solution of a problem of the same type (either compound or component), while interference resulted from prior solution of the other type of problem. The shift effects are interpreted in terms of Levine's $(1974,1975)$ transfer hypothesis and an extension of the attention theory of Zeaman and House $(1963,1974)$.
\end{abstract}

The present paper discusses the solution of compound and component problems and the interproblem transfer of these two solution modes from the viewpoint of attention theory (Zeaman \& House, 1963, 1974) and of hypothesis (H) theory (Levine, 1974, 1975). A proposed extension of attention theory that draws upon Haygood and Bourne's (1965) analysis of conceptual learning and that makes the same prediction for the outcome of the experiment reported in this paper as does the transfer hypothesis of $\mathrm{H}$ theory (Levine, 1974, 1975) is then offered. Following the presentation of this experiment, its theoretical implications are discussed.

\section{The Transfer of Compound and Component Solutions in Attention Theory}

Two types of solutions of discriminative problems have been distinguished: component solution (solution on the basis of component dimensional aspects of the stimulus array) and compound solution (solution on the basis of at least two aspects in combination). To illustrate, in terms of the standard form component problem of Figure 1, solution may be achieved by choosing the correct form component (square) regardless of its color (component solution), or by choosing the black square in Trial Setting 1 and the white square in Trial Setting 2 (compound solution). Other typical component problems, such as color or size problems, are analogous. For the color-form compound problem of Figure 1, however, since no component cue is consistently reinforced, the subject must leam to choose the black square in Trial Setting 1 and the white circle in Trial Setting 2. Thus, a component approach necessitates but

The authors are grateful to Betty J. House for her particularly helpful comments on this manuscript. Requests for reprints should be addressed to the first author at Rosemont College, Rosemont, Pennsylvania 19010. one solution, while a compound approach requires as many solutions as the number of trial settings.

A number of theorists view component solutions as mediated and thus conceptual in nature. Prototypical of these mediational accounts is the attention theory of Zeaman and House (1963), according to which such solutions require a two-stage process. An attentional response to a stimulus dimension is said to make available to the subject the cues along that dimension, and response is controlled by these cues. Evidence for the view of Zeaman and House (1963) is provided by the demonstration that following solution of an original learning (OL) problem, solution of a second problem with the same dimension relevant but with different cues-an intradimensional shift (IDS)-benefits from positive transfer, while solution of a second problem with a different relevant dimension and with new cues along previously variable dimensions-an extradimensional shift (EDS)-suffers from negative transfer. The transfer arrangements, thus, are such as to preclude specific cue transfer, and performance differences are explained as the result of transfer of the attentional response. A large number of experiments of this sort

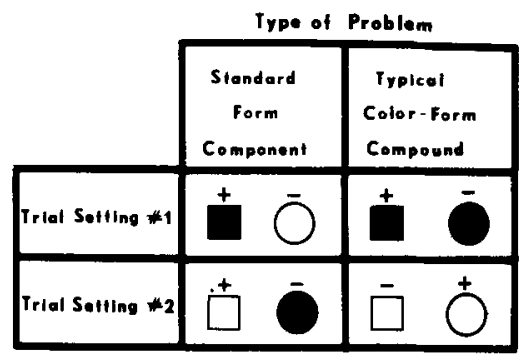

Figure 1. Example of a standard form component and typical color-form compound problem. The trial settings and the reinforcement positions within each problem are randomly alternated. 
have been summarized by Shepp and Turrisi (1966) and by Wolff (1967).

For Zeaman and House (House \& Zeaman, 1963; Zeaman \& House, 1963), compound solutions are mediated in the same manner, through the process of dimensional attention, as are component solutions. Compound dimensions are unitary dimensions in the same sense that component dimensions are. In terms of the compound problem of Figure 1, the correct attentional response would reveal the color-form cues black square and black circle on Trial Setting 1 and white square and white circle on Trial Setting 2. A number of theorists (Cole, 1973; Tighe, 1973; Tighe \& Tighe, 1972) were in essential agreement with Zeaman and House on the nature of component control of discriminative behavior (involving dimensional attention), but not on the nature of compound control. These theorists held that compound solutions involved only a single-stage object-reward relation.

Zeaman and House (1974) presented an attention theory model that explicitly incorporated attention to compound dimensions. Experimental evidence for their view was provided by Barnes (1978), who gave retarded subjects one of four two-problem sequences. The sequences were: (1) a form component problem followed by a second form component problem (an ID shift to a component problem), (2) a color-form compound problem followed by a form component problem (an ED shift to a component problem), (3) a color-form compound problem followed by a second color-form compound problem (an ID shift to a compound problem), and (4) a form component problem followed by a color-form compound problem (an ED shift to a compound problem). Dimensional transfer effects were obtained for compounds, as well as for components; solution of a compound problem during the shift phase was better if it followed the prior solution of a compound problem than if it followed the solution of a component problem. The outcome of this experiment was as predicted by Zeaman and House $(1963,1974)$, but not by those theorists who held that compound solutions are not conceptually mediated and involve only a single-stage mechanism.

Barnes (1978), however, employed the same relevant compound and component dimensions during OL and during shift. What would happen if subjects solved a compound problem following the solution of either a component problem or a prior compound problem that had a different compound dimension relevant, or if subjects solved a component problem following the solution of either a compound problem or a prior component problem with a different component dimension relevant? The experimental arrangements for such a shift comparison are shown in Table 1. These arrangements are analogous to those for an IDS-EDS comparison (cf. Shepp \& Turrisi, 1966; Zeaman \& House, 1963) and eliminate both specific cue transfer
Table 1

Experimental Arrangements for Demonstration of the Set-Selection Response

\begin{tabular}{|c|c|c|c|c|c|}
\hline \multirow[b]{2}{*}{ Group } & \multicolumn{2}{|c|}{$\begin{array}{l}\text { Original } \\
\text { Learning }\end{array}$} & \multicolumn{2}{|c|}{$\begin{array}{c}\text { Shift } \\
\text { Problem }\end{array}$} & \multirow{2}{*}{$\begin{array}{c}\text { Type } \\
\text { of } \\
\text { Shift }\end{array}$} \\
\hline & $\begin{array}{l}\text { Dimen- } \\
\text { sion }\end{array}$ & Cues & $\begin{array}{l}\text { Dimen- } \\
\text { sion }\end{array}$ & Cues & \\
\hline $\begin{array}{l}\text { Component-to- } \\
\text { Component }\end{array}$ & A & $a, b$ & B & $c, d$ & IS \\
\hline $\begin{array}{l}\text { Compound-to- } \\
\text { Component }\end{array}$ & $\mathrm{C}$ & $\begin{array}{l}\mathrm{e}, \mathrm{f}^{*} \\
\mathrm{~g}, \mathrm{~h}^{* *}\end{array}$ & B & $\mathrm{c}, \mathrm{d}$ & ES \\
\hline $\begin{array}{l}\text { Compound-to- } \\
\text { Compound }\end{array}$ & $\mathrm{C}$ & $\begin{array}{l}\mathrm{e}, \mathrm{f}^{*} \\
\mathrm{~g}, \mathrm{~h}^{* *}\end{array}$ & $\mathrm{D}$ & $\begin{array}{l}\mathrm{i}, \mathrm{j}^{*} \\
\mathrm{k}, \mathrm{I}^{* *}\end{array}$ & IS \\
\hline $\begin{array}{l}\text { Component-to- } \\
\text { Compound }\end{array}$ & A & $a, b$ & $\mathrm{D}$ & $\begin{array}{l}\mathrm{i}, \mathrm{j}^{*} \\
\mathrm{k}, \mathrm{l}^{* *}\end{array}$ & ES \\
\hline
\end{tabular}

Note-IS $=$ intraset shift, ES = extraset shift.

*Trial Setting 1 **Trial Setting 2

and transfer of the attending response to the specific dimension relevant in original learning. Facilitation of performance for the intraset shift (ISS) relative to that for the extraset shift (ESS) groups would support the assumption of a selective influence that acts before the attentional response and selects a set of dimensions (compound or component) for further processing. While the model of Zeaman and House (1974) does not speak to this issue, an expectation for better performance by the ISS than by the ESS groups may be derived from the theoretical writings of Levine (1974, 1975).

\section{The Transfer of Compound and Component \\ Solutions in $\mathbf{H}$ Theory}

An $\mathrm{H}$ is a solution prediction (e.g., "red" or "black") and is equivalent to the selection of a cue in the types of problems discussed in the present paper. The subject responds in accord with and tends to maintain the same $\mathrm{H}$ until it is disconfirmed. What influences the choice of the next $\mathrm{H}$ is of crucial importance to the present paper. $\mathrm{Hs}$ are chosen from a universe of Hs organized in terms of domains of related Hs. Levine (1974) tentatively defined domains as "sets of Hs that have relatively simple category labels" (p. 290). The transfer hypothesis states that a subject makes an inference that the solution to a new problem will come from the same domain to which solutions to previous problems belonged. The subject then approaches the new problem by sampling from that domain. The domain of simple solutions (e.g., color, shape) and that of conjunctive solutions are empirically equivalent to component and compound solutions, respectively. For Levine, then, transfer is determined by type of solution (domain) and the specific dimension involved. "The domain of simple $\mathrm{Hs}$ is divided into subdomains, each containing the $\mathrm{Hs}$ associated with a dimension" (Levine, 1974, p. 299). Levine $(1974,1975)$ applied the transfer hypothesis to an explanation of a variety of phenomena, including 
comparisons of reversal shift (RS) and nonreversal shift (NRS); such shifts are analogous, respectively, to IDS and EDS, except that new cues are not introduced on the shift problem (Shepp \& Turrisi, 1966). While Levine did not specifically apply the transfer hypothesis to IDSEDS effects as distinct from RS-NRS effects, an explanation of IDS-EDS effects within the theoretical confines of the transfer hypothesis would be identical to an explanation of RS-NRS effects. The transfer hypothesis thus predicts shift effects of the type obtained in IDS-EDS comparisons in an ISS-ESS comparison using the arrangements shown in Table 1.

\section{An Extension of Attention Theory}

Attention theory, if it is modified by the addition of a third link that operates prior to the two traditional links of the attentional response and cue selection, will make the same prediction as the transfer hypothesis with regard to the outcome of an experiment such as that suggested in Table 1. This additional link would select a set of dimensions (compound or component) for further processing. Such a set-selection response (or rule-selection mechanism) would appear to be indicated by the work of Haygood and Bourne (1965), who experimentally separated concept learning into attribute identification (isolation of the relevant attributes, e.g., red and square) and rule learning (discovering the "conceptual rule by which the attributes are combined to form the concept," p. 175, e.g., conjunction) and showed that knowledge of either aspect speeded learning compared to the condition in which subjects were informed of neither. In the context of the Haygood and Bourne research, the set-selection response can be seen as analogous to rule learning; that is, making the setselection response to the set of component dimensions is analogous to learning the rule "affirmation," and making the set-selection response to compounds is analogous to learning the rule "conjunction." The two traditional links of attention theory, the attending response and cue selection, are analogous to attribute identification. While there are similarities between our proposed extension of attention theory and the analysis of Haygood and Bourne, there are also differences. One such difference is that Haygood and Bourne viewed a conjunctive problem as bidimensional, while the present analysis takes the view that a conjunctive problem is unidimensional, and that the joint presence of attributes from different dimensions constitutes a unitary compound cue (e.g., red square).

The experiment reported in the present paper used the arrangements of Table 1 . For such an experiment, unextended attention theory is silent, while the expectations that may be derived from Levine's $(1974,1975)$ transfer hypothesis and from the extension of attention theory presented here are clear: Transfer effects analogous to the dimensional transfer effects of an IDS-EDS comparison should be obtained in the ISS-ESS comparison. Such results would be interpretable as support for the transfer hypothesis and as an indication of a need for an extension of attention theory along the lines indicated in the present paper. A lack of a shift effect in the ISS-ESS comparison would indicate that present attention theory does not need an extension and that transfer predictions based on the transfer hypothesis are overly general.

\section{METHOD}

\section{Subjects}

The subjects for this experiment were 80 undergraduate women at Rosemont College who were volunteers; neither pay nor course credit was given for participation.

\section{Stimulus Materials}

All stimuli were colored forms, produced from acrylic paint, that appeared in the centers of 9-cm white cardboard squares. All colors were readily discriminable from each other. Several types of stimuli were necessary for the several different types of problems.

Stimuli for form component and color-form compound problems. The combinations of 10 colors (brown, red, black, ochre, light green, purple, blue, maroon, yellow, and dark green) and 10 forms (block $\mathrm{H}$, block $\mathrm{T}$, triangle, square, heart, circle, star, football shape, cross, and block X) produced 100 color-form stimuli. These stimuli were of approximately the same area and had a maximum height and width of $4 \mathrm{~cm}$.

Stimuli for size component problems. Five of the previously mentioned forms (block $\mathrm{H}$, block $\mathrm{T}$, triangle, square, and star) were factorially combined with all 10 of the previous colors and two sizes, large (maximum height and width of $4 \mathrm{~cm}$ ) and small (maximum height and width of $2 \mathrm{~cm}$ ) to produce 100 size stimuli.

Stimuli for texture-size compound problems. Large and small (same measurements as for size component stimuli) brown block Hs, black block Ts, ochre triangles, purple hearts, and blue circles were made in each of two textures, smooth and rough, to produce 20 texture-size stimuli. Smooth stimuli were made by applying the acrylic paint as smoothly as possible to the cardboard squares, while the rough stimuli were produced by piling the paint up to produce very noticeable blobs and spines.

\section{Design and Problems}

Twenty subjects were assigned to each of the four groups generated by the factorial combinations of type of dimension relevant on original learning (component or compound) and type of dimension relevant on the shift problem (component or compound). Specifically, in the group that was given a componentto-different-component sequence, 10 subjects received a form problem followed by a size problem, and 10 subjects a size problem followed by a form problem. In the second group, which received a compound-to-component sequence, 10 subjects were given a color-form compound problem followed by a size problem, and 10 subjects a texture-size compound problem followed by a form problem. In a third group, which was presented with a compound-to-different-compound sequence, 10 subjects received a color-form compound problem followed by a texture-size compound problem, and 10 subjects a texture-size compound problem followed by a color-form compound problem. A final group was given a component-to-compound sequence, and in this group, 10 subjects solved a form problem followed by a texture-size problem, and 10 subjects a size problem followed by a color-form compound problem. The problems were constructed as follows.

Form component problems. For each subject, one form is consistently correct, another is consistently incorrect. The use 
of 10 different trial settings (with a different color on each trial setting) was to insure that the problems would be solved on the basis of form and not as color-form compound problems, a solution that would require the learning of 10 separate problems. Trials were in blocks of 10 , with each trial setting occurring once within each block. Order of presentation of trial settings within a block was random, with the restriction that the first trial setting of any block not be the same as the last of the preceding block. An example of this type of problem is shown in Figure 2.

Size componest problems. The construction and presentation of size problems were analogous to those of the form problems. Again, 10 trial settings were used to guard against the possibility of compound solutions. An example of this type of problem is shown in Figure 2.

Color-form compound problems. Problems of this type consisted of two trial settings (position disregarded), with a different color-form compound correct on each trial setting. Reinforcement depended solely on the color-form compound neither the values along the color dimension nor those along the form dimension were correlated with reinforcement. The two trial settings were randomly alternated with the following restrictions. Neither setting occurred more than three times in a row, and each appeared five times within each block of 10 trials. Each of the four trial-setting/reinforcement-position combinations occurred not less than 6 nor more than 7 times within each block of 25 trials, and not less than 12 nor more than 13 times within any block of 50 . An example of this type of problem is shown in Figure 2.

Texture-size compound problems. These problems were constructed and presented in a manner analogous to the color-form problems. The texture-size compounds are the only features of these problems that are correlated with reinforcement. An example of this type of problem is shown in Figure 2.

Controls. Fot each of the four types of problems, 10 specific problems were constructed such that the second 5 were reversals of the first 5 . One of the 10 specific problems was assigned to each member of a subgroup (e.g., the 10 subjects in the

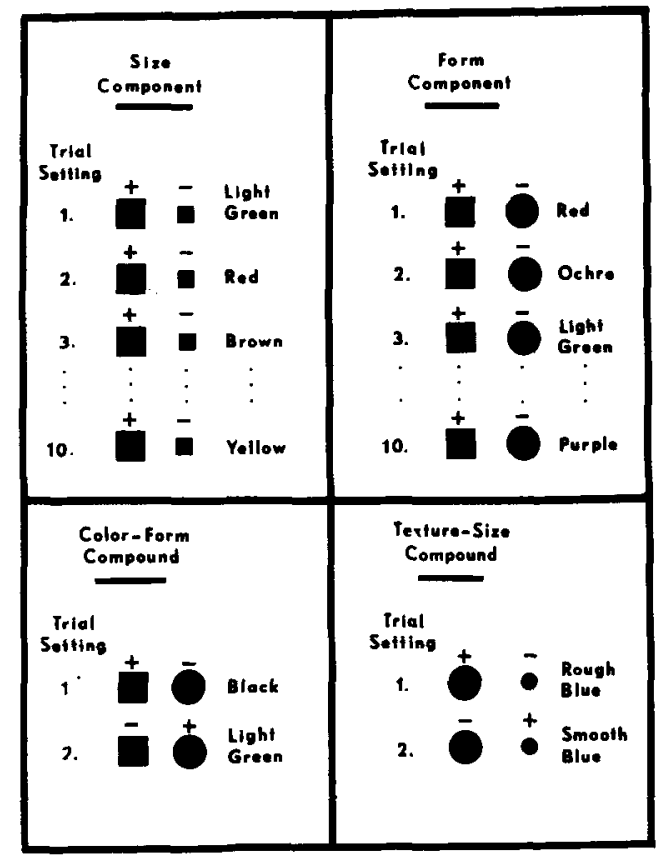

Figure 2. Examples of the problems used in the present experiment. component-to-component sequence group who received a form problem followed by a size problem) receiving that type of problem. This was done as a control for cue preferences. Correlation of position with reinforcement was avoided by use of a Gellermann (1933) series. These controls were used for the problems administered both on OL and on shift.

\section{Procedure}

Subjects, who were tested individually and were told that they were going to participate in a learning experiment, were seated across a table from the experimenter and were separated from her by a screen $10.5 \mathrm{~cm}$ in height that shielded the stimulus cards not presently in use from the subject. Subjects were then presented with two stimulus cards at a time and were told to touch the card they thought was correct and to try to be correct on every trial. They were run to a criterion of 10 correct trials in a row on the original problem and were then immediately given the shift problem, which also had a criterion of 10 correct trials in a row, but which neither used special training nor had any upper limit on errors. Those who did not solve the original problem within 50 trials were given special training similar to that used by Barnes (1978), Campione (1970), and Eimas (1966). This involved showing the subjects all the correct and incorrect stimuli (either 2 or 10) and stating that they were correct and incorrect, respectively. They again received the standard training until a criterion of 10 consecutive errorless trials was reached, at which point they were given the shift problems. On the shift problem, each subject received a set of stimulus cards with forms different from those used during original learning.

\section{RESULTS}

In order to make the data more closely fit the assumptions of parametric statistics, all analyses were performed using $\log$ (errors +1 ) as the dependent variable, and descriptive statistics are given in terms of geometric means (errors +1 ).

\section{Original Learning}

Only three subjects, two in the compound-tocomponent group and one in the compound-to-differentcompound group, needed special training. None of these made any additional errors after being given special training.

The geometric mean error scores for each of the four groups were as follows: component-to-component, 2.1 ; compound-to-component, 5.8; compound-tocompound, 4.4; and component-to-compound, 2.2. A preliminary analysis indicated that the two groups solving an initial component problem did not differ significantly from each other, nor did the two groups solving an initial compound problem.

Those subjects who solved an initial component problem had a geometric mean error score of 2.1, while those who solved an initial compound problem had a geometric mean error score of 5.1. This difference was statistically reliable $[\mathrm{t}(78)=5.54, \mathrm{p}<.001]$. The finding of better performance on a component than on a compound problem is consonant with previous results obtained with college students by Zeaman and House (1974). 


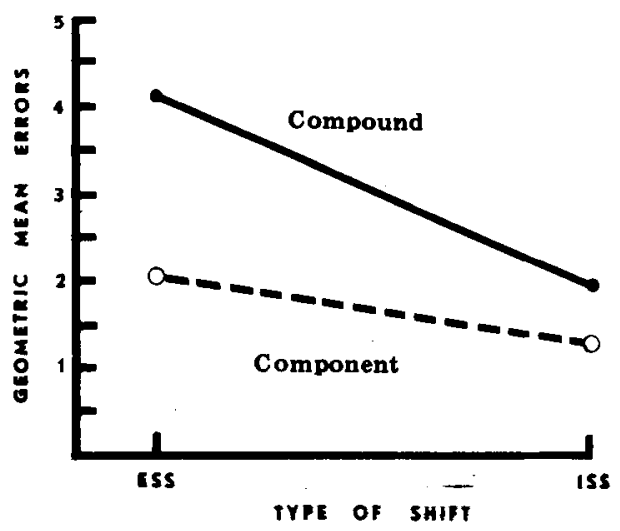

Figure 3. Performance on the shift problem as a function of type of shift (ESS or ISS) and type of problem (compound or component).

\section{Shift Problem}

Performance on the shift problem can be seen in Figure 3. A 2 by 2 analysis of variance (type of dimension, component vs. compound, relevant during shift by type of shift, IS vs. ES) revealed that both main effects were statistically significant, but that their interaction was not. Those subjects solving a compound problem had a geometric mean error score of 2.9 , and those solving a component problem, 1.7 , a reliable difference $[F(1,76)=22.76, p<.001]$. Subjects who were given IS and ES shifts had geometric mean error scores of 1.6 and 2.9 , respectively, also a reliable difference $[F(1,76)=26.84, p<.001]$. The rather good performance by those subjects who solved a component problem as an ESS may presumably be understood in terms of the simplicity of component problems for college students.

The three subjects who required special training on the initial problem made only one error apiece during shift.

\section{DISCUSSION}

The results of this experiment suggest a selective influence prior to the selection of specific dimensions. Such a selective influence is predicted by Levine's (1974, 1975) transfer hypothesis (sampling in the same domain) and by the extension of the Zeaman and House (1963, 1974) attention theory offered in this paper, but not by unextended attention theory. The strongest conclusion, then, that can be drawn from the present data is that attention theory needs the additional link provided by the set-selection response (or rule-selection mechanism). In the absence of differential predictions for the shift problem, one has to look elsewhere for reasons to prefer either $\mathrm{H}$ theory with the transfer hypothesis or the present extension of attention theory, which was indicated by the Haygood and Bourne (1965) analysis of concept learning. While they make the same outcome predictions for the present research, they are clearly not of one voice with respect to all other relevant phenomena. Which of the two approaches is to be preferred is a question that must ultimately be decided by which gives a better account of the whole range of discriminative learning and transfer phenomena.

The significant ISS-ESS difference reported in the present paper also provides additional support for the earlier claims for conceptual mediation of compound solutions made by Barnes (1978) and by Zeaman and House (1974).

\section{REFERENCES}

Barnes, T. R. Transfer of compounds and components in the discriminative learning of retardates. Joumal of Experimental Child Psychology, 1978, 25, 71-79.

CAMPIONE, J. C. Optional intradimensional and extradimensional shifts in children as a function of age. Journal of Experimental Psychology, 1970, 84, 296-300.

COLE, M. A developmental study of factors influencing discrimination transfer. Journal of Experimental Child Psychology, 1973, 16, 126-147.

Eimas, P. D. Effects of overtraining and age on intradimensional and extradimensional shifts in children. Journal of Experimental Child Psychology, 1966, 3, 348-355.

Gellermann, L. W. Chance orders of alternating stimuli in visual discrimination experiments. Journal of Genetic Psychology, 1933, 42, 206-208.

Haygood, R. C., \& Bourne, L. E., JR. Attribute- and rulelearning aspects of conceptual behavior. Psychological Review, $1965,72,175-195$.

House, B. J., \& Zeaman, D. Miniature experiments in the discrimination learning of retardates. In L. P. Lipsitt \& C. C. Spiker (Eds.), Advances in child development and behavior (Vol. 1). New York: Academic Press, 1963.

LEVINE, M. A transfer hypothesis, whereby learning-to-learn, Einstellung, the PREE, reversal-nonreversal shifts, and other curiosities are elucidated. In R. L. Solso (Ed.), Theories in cognitive psychology: The Loyola symposium. Potomac, Md: Lawrence Erlbaum, 1974.

Levine, M. A cognitive theory of learning: Research on hypothesis testing. Hillsdale. N.J: Lawrence Erlbaum, 1975.

ShEPP, B. E., \& TURRISI, F. D. Learning and transfer of mediating responses in discriminative learning. In N. R. Ellis (Ed.), Intermational review of research in mental retardation (Vol. 2). New York: Academic Press, 1966.

Tighe, T. J. Subproblem analysis of discrimination learning. In G. H. Bower (Ed.), The psychology of learning and motivation (Vol. 7). New York: Academic Press, 1973.

Tighe, T. J., \& Tighe, L. S. Stimulus control in children's learning. In A. D. Pick (Ed.), Minnesota symposia on child psychology (Vol. 6). Minneapolis: University of Minnesota Press, 1972.

WolfF, J. L. Concept-shift and discrimination-reversal learning in humans. Psychological Bulletin, 1967, 68, 369-408.

Zeaman, D., \& House, B. J. The role of attention in retardate discrimination learning. In N. R. Ellis (Ed.), Handbook of mental deficiency. New York: McGraw-Hill, 1963.

ZeAmaN, D., \& House, B. J. Interpretations of developmental trends in discriminative transfer effects. In A. D. Pick (Ed.), Minnesota symposium on child development (Vol. 8). Minneapolis: University of Minnesota Press, 1974.

(Revision accepted for publication October 16, 1978.) 